\title{
The Upper-Great Lakes Observing System
}

\author{
Hunter C. Brown, Heidi L. Purcell, Guy A. Meadows \\ University of Michigan \\ Department of Naval Architecture \& Marine Engineering \\ Ann Arbor, Michigan 48109 \\ email: \{hcbrown, hpurcell, meadows $\} @$ umich.edu
}

\begin{abstract}
This paper reports an overview of the University of Michigan's Upper-Great Lakes Observing System (U-GLOS) program, as well as the design, construction, and testing of offshore buoy platforms, communication schemes, and a shorebased server system. Since 2003, the University of Michigan's Marine Hydrodynamics Laboratories (MHL) has partnered with local communities, as well as Northwestern Michigan's College Water Studies Institute, DTE, Alliance for Coastal Technologies, Michigan Sea Grant, and the Grand Traverse Band of Ottawa and Chippewa Indians to develop the U-GLOS program that exists today. The U-GLOS program now includes both land and offshore platforms that monitor environmental conditions and report, in real-time, the results to a publicly accessible web site. Each station measures a wide range of properties including air temperature, wind speed, wind gusts, solar radiation, humidity, and more. Buoy stations also measure water temperature (thermistor array), directional and non-directional wave characteristics. Ongoing scientific and engineering research is discussed, as well as an overview of available data products, quality control and quality assurance algorithms, and conformity to the National Data Buoy Center (NDBC) standards.
\end{abstract}

\section{INTRODUCTION}

In 2003, the MHL was invited to participate in the establishment of the Great Lakes Observing System (GLOS). GLOS is one of 11 regional associations within the U.S. Integrated Ocean Observing System (IOOS), a National Oceanic and Atmospheric Administration (NOAA) funded program.

During the fledgling years, GLOS resources were focused on assessing the observational needs of potential users, and the development of the organization's business plan and its incorporation. Funding during this time was not available for open water monitoring. The MHL therefore partnered with Northwestern Michigan College's Water Studies Institute, the Great Lakes Maritime Academy, Michigan Sea Grant, and the Grand Traverse Band of Ottawa and Chippewa Indians to deploy the first U-GLOS coastal monitoring buoy. With help from the Great Lakes Maritime Academy, the MHL deployed an Aanderaa buoy in the west arm of Grand Traverse Bay. This buoy was the first deployed in the bay that transmitted real-time data directly to a website accessible by the general public. This initial deployment demonstrated the importance of real-time data to not only scientists and resource managers, but to the local communities as well.

In 2006 DTE Energy, recognizing the benefit of such data for the Grand Traverse communities, joined with the Alliance for Coastal Technologies (ACT) and Northwestern College's Water Study Institute to help fund the MHL's purchase of a new Aanderaa coastal monitoring buoy for deployment in Grand Traverse Bay. ACT acts as a third party test bed for coastal sensor technologies and is currently working on the development of protocols for a National Wave Technologies Test and Evaluation as described in IOOS's National Operational Wave Observation Plan. As the Great Lakes Partner of ACT, the University of Michigan will play a key role in protocol development. ACT also contributed a shore-based station that was installed on the pier of The Great Lakes Maritime Academy.

In 2008, GLOS funding allowed the MHL to refurbish and deploy the original Aanderra buoy as well as develop a better sensor suite to include on future buoys. This system also included the MHL-designed inertial wave sensor. 2009 brought two new buoys on line for U-GLOS, even though the GLOS near-shore network funding was cut back. The MHL then transferred the newly developed technologies to S2 Yachts, a Holland, Michigan yacht manufacturer interested in diversifying its product lines.

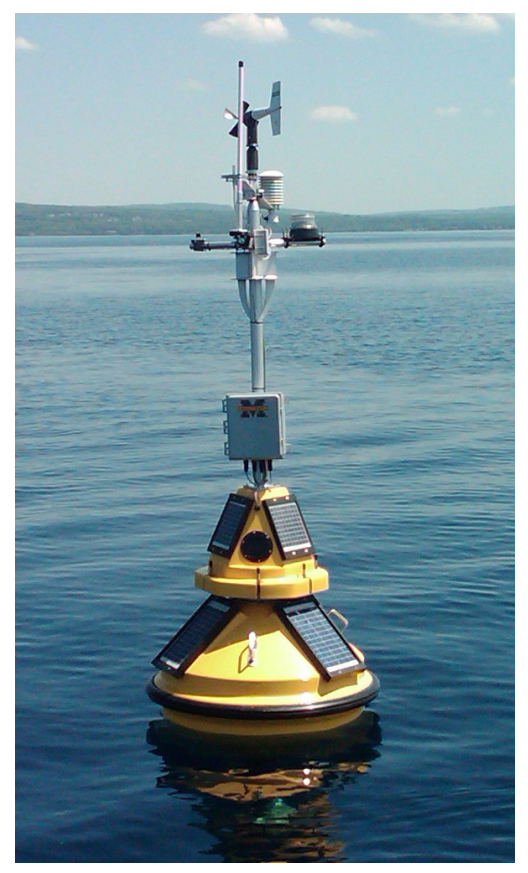

Fig. 1. MHL and S2 designed buoy deployed in Little Traverse Bay.

The first S2 TIDAS 900 buoy (Total Integrated Data Acquisition System) was deployed in Little Traverse Bay. This 
was made possible only through cooperative efforts with the local businesses and communities of Harbor Springs and Petoskey. In exchange for the MHL's purchase of the buoy, the communities have agreed to service and maintain the buoy. With the concern of global warming coming to the forefront, many consumers of the buoy data products were interested in thermal stratification in the areas the buoys were monitoring. The MHL received funding through Northwestern College from the Grand Traverse Band of Ottawa and Chippewa for the design and fabrication of a thermistor string buoy for deployment north of Mission Point in Grand Traverse Bay.

\section{System OVERVIEW}

The Upper-Great Lakes Observing System is comprised of shore-based monitoring stations as well as moored-buoy stations deployed in Grand Traverse and Little Traverse Bay, and near Calumet, MI in Lake Superior. Each monitoring station measures environmental conditions and reports the realtime data via cellular network connection to shore-based data servers. Similar to the SAIC COBIA buoy model [1], the UGLOS buoys use many commercial-off-the-shelf components and are built with modularity in mind, with reserve expansion ports, to fulfill many scientific and community based needs.

\section{A. Buoy Platform}

Each offshore buoy platform consists of an anchor, mooring line, and environmental buoy. The single point mooring system is designed for ease of deployment and retrieval with a small vessel. The anchor, a $453 \mathrm{~kg}(1000 \mathrm{lb})$ concrete block, has performed well against normal wind and wave conditions experienced in the western bays of Michigan and in southern Lake Superior. The MHL has taken special care in the design of the mooring mount to preclude entanglement with the optional thermistor string attachment.

The buoy itself has four sections (Figure 1). A central spar with integrated weight acts as a keel weight to maintain proper buoy orientation. This spar runs through the flotation hull, and is also used to store batteries as well as providing a mounting surface for the optional thermistor string and MHL Inertial Wave Sensor. The flotation hull mounts to the keel spar and provides buoyancy and a mounting point for three larger solar panels. The upper buoy seals via a rubber gasket to the flotation hull, and can be detached for service on the deck of a support vessel. Three smaller solar arrays, the central processing system, and the sensor mast are housed in the upper buoy. The sensor mast supports the majority of environmental sensors included on the buoy (see Table I).

In addition to the $45 \mathrm{~kg}(100 \mathrm{lbs})$ of removable modular ballast on the spar, and the $72 \mathrm{~kg}(160 \mathrm{lbs})$ of suspended ballast (if not using the optional thermistor string), the weight of the MHL buoy is approximately $159 \mathrm{~kg}(350 \mathrm{lbs})$. The National Data Buoy Center (NDBC) Standard Buoy Model [2], in comparison, has a diameter of $2.3 \mathrm{~m}(7.5 \mathrm{ft})$ and weighs approximately $953 \mathrm{~kg}(2,100 \mathrm{lbs})$ overall. The relatively small size allows the U-GLOS buoy to be deployed from a small boat without an A-frame.

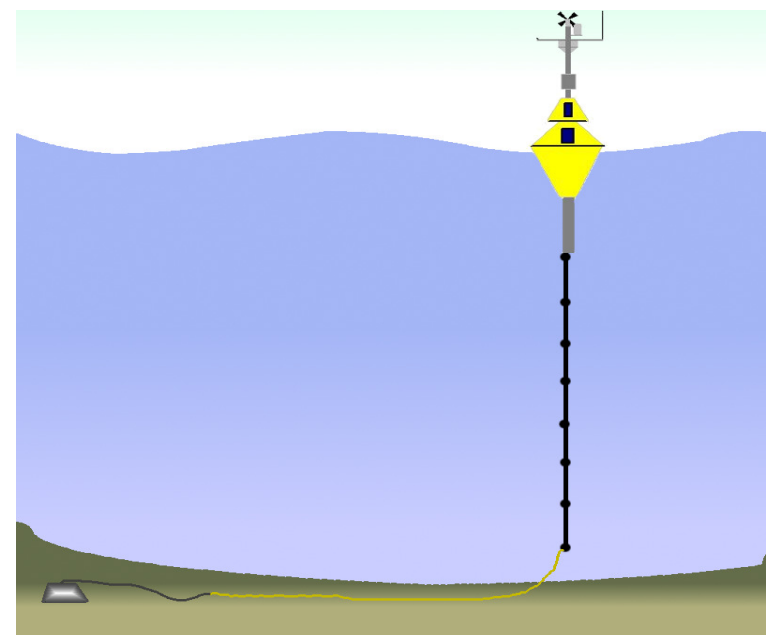

Fig. 2. Buoy 45023 mooring schematic.

a) Mooring Design: All U-GLOS buoys use a singlepoint mooring system held in place by a $453 \mathrm{~kg}(1000 \mathrm{lb})$ concrete clump weight (Figure 2). Attached to the clump

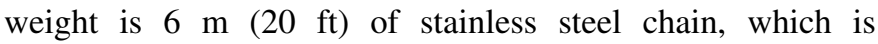
connected by thimble to a $2.5 \mathrm{~cm}$ (1 in) nylon or polypropylene line depending on the sensor options. Buoys equipped with optional thermistor strings use a negatively buoyant nylon line while those without the string use a positively buoyant polypropylene line. The nylon line is ballasted with a small weight at the end of the thermistor string, of approximately 14 $\mathrm{kg}$ (30 lbs). The polypropylene line is connected to a swivel mounted on the buoy with approximately $59 \mathrm{~kg}(130 \mathrm{lb})$ of ballast weight. The line length is determined by the distance from the concrete clump weight to the water surface.

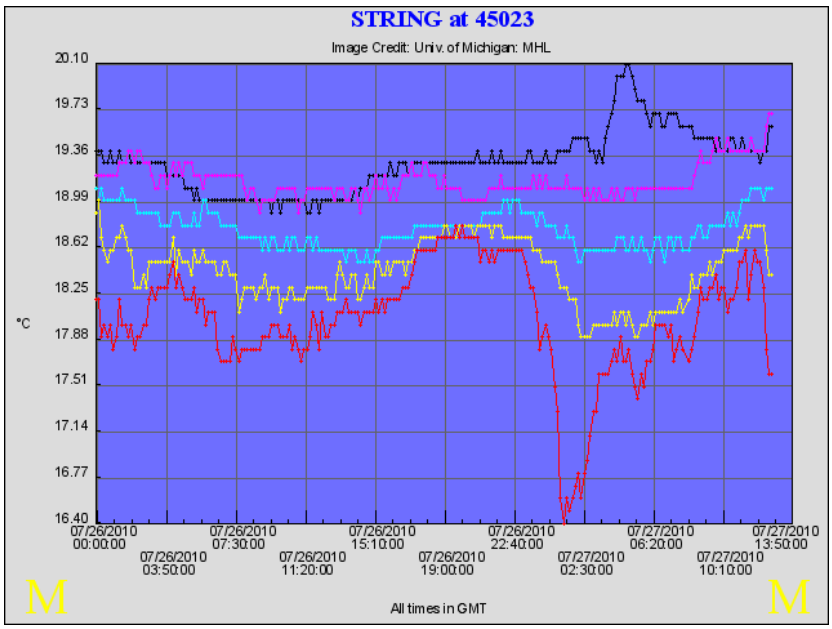

Fig. 3. Example output from thermistor equipped buoy.

b) Keel Spar: The buoy keel spar serves as both a battery housing and as an attachment point for the mooring line and the optional thermistor string. Installed within the spar are three packs of six $2.2 \mathrm{~V}$ cells, which provide $13.2 \mathrm{~V}$ power for the onboard processing as well as cellular network data 
TABLE I

INTEGRATED SENSORS ON THE U-GLOS BUOYS.

\begin{tabular}{|c|c|c|c|c|}
\hline SENSOR & VARIABLE & SAMPLE RATE & ACCURACY & RANGE \\
\hline RM Young 09101 & Wind Speed, Direction & $1 \mathrm{~Hz}$ & $\pm 3 \mathrm{~m} / \mathrm{s}$ or $1 \%$ (Speed), $\pm 2^{\circ}$ (Dir.) & $0-100 \mathrm{~m} / \mathrm{s}$ (Speed), $0-360^{\circ}$ (Dir.) \\
\hline Apogee SP-212 & Solar Radiation & $1 \mathrm{~Hz}$ & $\pm 5 \%$ & - \\
\hline LI-COR LI-200 & Solar Radiation & $1 \mathrm{~Hz}$ & $\pm 5 \%$ & - \\
\hline MHL Thermister String & Water Temperature & $1 \mathrm{~Hz}$ & $\pm 0.5^{\circ} \mathrm{C}$ & $-65^{\circ} \mathrm{C}$ to $+150^{\circ} \mathrm{C}$ \\
\hline RM Young 41382 & Humidity, Air Temperature & $1 \mathrm{~Hz}$ & $\pm 2 \%(\mathrm{RH}), \pm 0.3^{\circ}$ (Temp) & $0-100 \%(\mathrm{RH}),-50^{\circ} \mathrm{C}$ to $+150^{\circ} \mathrm{C}$ \\
\hline RM Young 61202V & Barometric Pressure & $1 \mathrm{~Hz}$ & $\pm 1 \mathrm{hPa}$ at $-50^{\circ} \mathrm{C}$ to $+60^{\circ} \mathrm{C}$ & $600-1100 \mathrm{hPa}$ \\
\hline MHL Inertial Wave Sensor & $\begin{array}{c}\text { Non-directional and } \\
\text { directional wave parameters }\end{array}$ & $1 \mathrm{~Hz}$ & TBD & TBD \\
\hline
\end{tabular}

transmission. A $45 \mathrm{~kg}$ (100lb) lead ballast weight is bolted to the spar, beneath the flotation hull, with an additional $72 \mathrm{~kg}$ (160 lbs) hung from the base of the keep to provide a rightingmoment and damping of the buoy motions during sea-surface oscillations.

An optional MHL-designed thermistor string can be attached to the base of the keel spar to record temperatures at varying depths. The thermistor string is composed of eight thermistor nodes and can be expanded to 16 nodes, with each node permanently positioned along a cable at the desired measurement depth. Each node of the thermistor string has a sample rate of $1 \mathrm{~Hz}$, and is accurate to within $\pm 0.5^{\circ} \mathrm{C}$ over a temperature range of $-65^{\circ} \mathrm{C}$ to $+150^{\circ} \mathrm{C}$. Figure 3 shows an example graph, taken from the public website http://uglos.engin.umich.edu, displaying temperature data from five of the eight nodes over a time span of two days. Thermoclines are easily visible and mixing phenomena can be observed in real time. If the thermistor string is deployed, 90 $\mathrm{kg}(200 \mathrm{lbs})$ of lead ballast will be attached to the spar and the thermistor/weight system provides an additional $27 \mathrm{~kg}$ (60 lbs)

Also housed inside the buoy keel spar is the MHL-designed Inertial Wave Sensor (IWS) (Figure 4). The IWS uses a highprecision Honeywell digital compass that reports roll and pitch angles in addition to heading, and a three-axis accelerometer to determine directional and non-directional wave characteristics. The NDBC has developed a strong program for the measurement of environmental data including wave measurement using many well-known papers ( [3]-[5]). The MHL IWS follows the standards set forth by the NDBC, but performs all calculations on a low-power Rabbit RCM3600 embedded controller. Inertial samples are recorded at a rate of $4 \mathrm{~Hz}$ and analyzed in 256 second bins. Four sets of 256 second bins are then averaged to achieve a total record length of 1024 seconds, thereby minimizing spectral leakage according to Tucker's 1991 paper [6]. Each sensor has a built-in calibration routine for both accelerometer and compass declination adjustment. Bin size, total number of bins, and reporting mode can all be modified remotely through an RS-232 interface. Investigations of global positioning system (GPS) based solutions, similar to work at Ohio State University, the National Cheng Kung University in Taiwan and collaborative efforts in South Korea are ongoing [7]-[10].

c) Flotation Hull: The flotation hull is a $1.2 \mathrm{~m}$ (4 $\mathrm{ft}$ ) diameter foam-infused fiberglass frame with aluminum

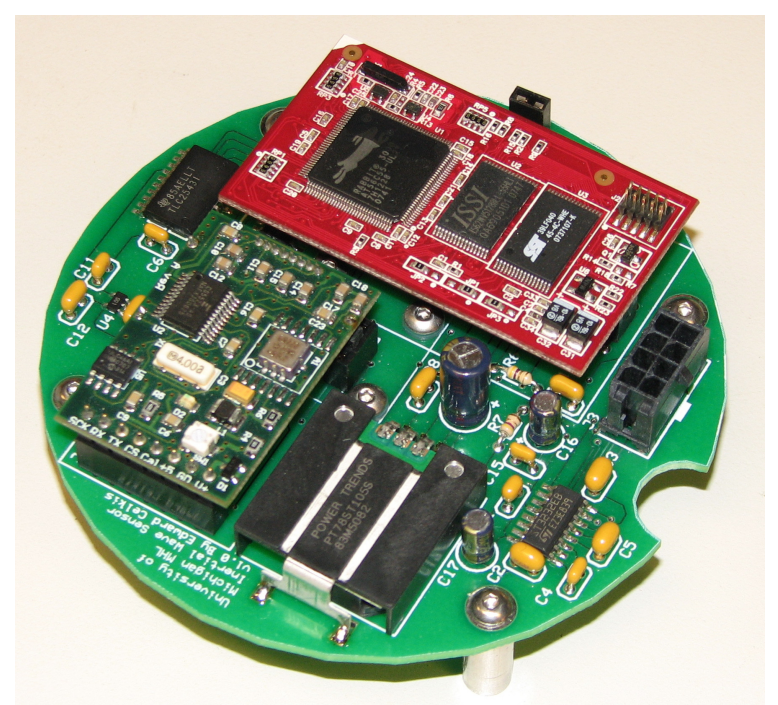

Fig. 4. MHL-designed IWS.

structural members. Three solar panels, $22 \times 33 \mathrm{~cm}(9 \times 13$ in) each, are arranged at 120 degree offsets to provide for the maximum allowable solar insolation independent of buoy heading and orientation. Each solar array produces 10 Watts of energy in full sunshine, yielding 30 Watts total from the flotation hull.

d) Upper Buoy: The upper buoy contains a set of three smaller solar panels, $21 \times 20 \mathrm{~cm}(8.5 \times 8$ in), providing 5 Watts of energy during full sun light, for a total of 15 Watts from the upper buoy. Also housed in the upper buoy is the control box seen in Figure 5. The control box contains the data logger, cellular telephone modem, thermistor string controller circuit boards, and expansion space for mission-specific electronics. The control box can also be installed on the sensor mast. A removable panel in the upper buoy provides access to electrical connections inside the hull, allowing for easy removal of the upper hull while the buoy is deployed.

e) Sensor Mast: A sensor mast is attached to the upper buoy and serves as a mounting platform for the environmental sensors, cellular telemetry antenna, as well as a navigation light and radar reflector, as required by the U.S. Coast Guard. Mounted to the sensor mast is an R.M. Young 09101 anemometer, R.M. Young 41382 humidity sensor, R.M. Young $61202 \mathrm{~V}$ pressure sensor, and Licor LI-200 or SP-212 solar 


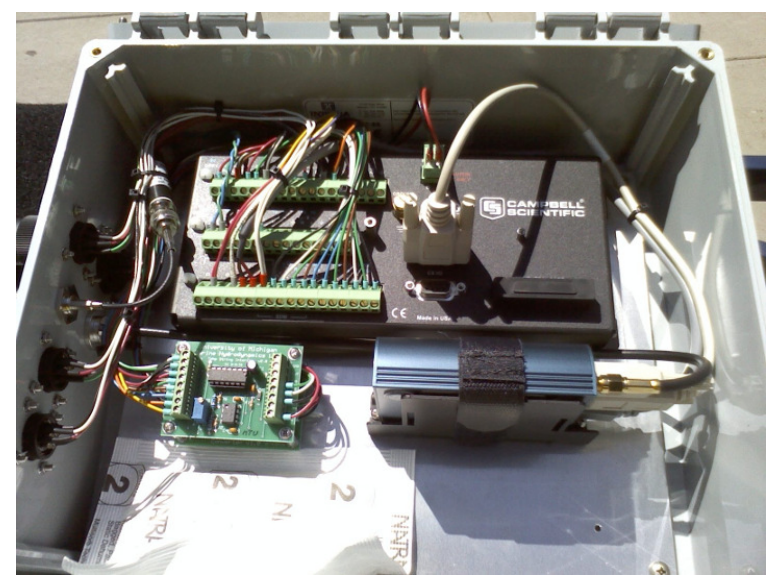

Fig. 5. The control box mounted inside the upper hull or on the sensor mast.

radiation sensor (see Table I).

A review of existing telemetry technologies such as 900 $\mathrm{MHz}$ wireless radios, cellular telephone, and satellite-based telephone systems was conducted prior to selecting a specific technology for inclusion on the U-GLOS buoys [11], [12]. Wireless radio links were abandoned due to the shore-based station installation requirements, and satellite telemetry was removed from consideration due to high service costs. Transmission distances for both the $900 \mathrm{MHz}$ and cellular systems are similar, so no advantage is gained from the additional effort to install shore stations. In addition, the U-GLOS buoys are typically deployed within a five-mile radius of land, well within the standard cell network coverage. A cellular network communication system was eventually chosen to leverage existing cellular infrastructure, thus minimizing deployment efforts and keeping system costs low. An optional transmission system using satellite telemetry is available but rarely used due to cost.

\section{B. Shore-based Data Server}

A dedicated Linux-based server at the MHL gathers realtime environmental data from all U-GLOS stations and provides a web portal through which the general public, as well as scientists, can interact with the historical and current buoy data. The website structure, which conforms to the NDBC standards, creates real-time data tables as well as visualization tools to assist with data comprehension (Figure 6).

Every ten minutes, each buoy constructs an Extensible Markup Language (XML) file containing the latest data measurements and connects to the internet via a cellular network modem. The buoy then uploads, via FTP (File Transfer Protocol), the XML file to several shore-stations such as the MHL, GLOS, and NDBC. The MHL server scans for newly uploaded XML files from all active stations every four minutes and automatically parses each file for insertion into an SQL database. If a station does not transmit a data file successfully within the most recent hour, a special marker is displayed on the MHL website, similar to the NDBC web site, to indicate the buoy is unaccounted for. Monthly backups of the SQL database are stored on a redundant networked system located at a remote facility.

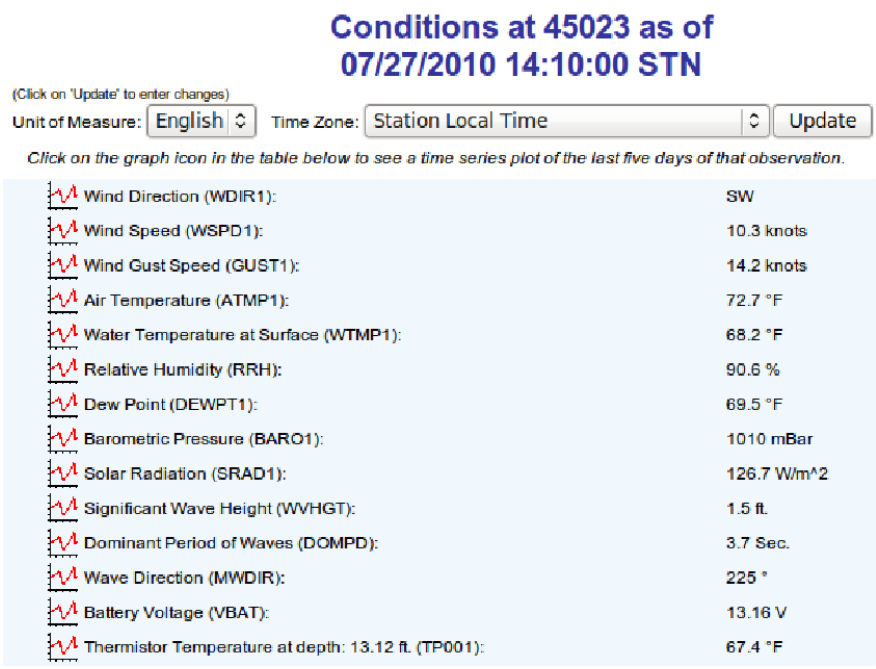

Fig. 6. UGLOS website portion displaying the current conditions as measured by Lake Superior buoy 45023 .

Student teams are currently working to implement a new quality assurance (QA) and quality control (QC) system within the U-GLOS system architecture. Upon receipt of each data package from the buoys, a full $\mathrm{QA} \backslash \mathrm{QC}$ package will be applied to the data. This $\mathrm{QA} \backslash \mathrm{QC}$ procedure is outlined in the 2009 NDBC Handbook of Automated Data Quality Control Checks and Procedures technical document [13]. The NDBC handbook recommends testing for typical errors such as outlier data, spurious data, and missing data due to non-functioning sensors. Currently, the U-GLOS system reports raw sensor data; the new $\mathrm{QA} \backslash \mathrm{QC}$ tests and others will be in place for the 2011 deployment.

Geographic locations of each buoy are displayed through the use of the freely available Google Maps JavaScript API (Application Programming Interface) from Google (Figure 7). The JavaScript API is protected via a host-specific domainkey to protect against counterfeit requests. The MHL U-GLOS web site is primarily written in PHP (Hypertext Preprocessor), a server-side scripting language, which generates both HTML (HyperText Markup Language) content and data display images, and uses CSS (Cascading Style Sheets) for formatting. The U-GLOS website provides access to not only real-time data, but time-series graphs of environmental conditions, and optional historical data downloads from any station.

\section{Deployments}

Currently, the U-GLOS program has five buoys deployed in the upper Great Lakes. The most recent addition was deployed on July 8, 2010, just offshore of Houghton, Michigan in Lake Superior. This buoy, NDBC 45023, was designed and fabricated for Michigan Technological University (MTU) by the MHL in partnership with Michigan Tech Research Institute (MTRI). This buoy, as well as buoy 45022 deployed on May 25, 2010 in Little Traverse Bay, Michigan, have been 
continuously reporting data since deployment and are expected to provide continuous data monitoring through retrieval in October. Other environmental buoys without solar harvesting technologies, such as the Pioneer buoys described in [14], report active mission durations of roughly 21 to 60 days before service maintenance is required.

MTU and the communities surrounding the Grand Traverse and Little Traverse Bay areas are actively using station data for research and recreational activities. MTU is using data from buoy 45023 to design new mixing models for southern Lake Superior, as well as to enhance climatological forecasting models in the area. The modeling groups have 144 samples per day (six per hour) to construct dense meteorological and oceanographic data records for testing and verifying new models. The cities of Petoskey and Harbor Springs have used wind and wave measurements for small craft warnings and advisories, and even event planning for activities on the bays.

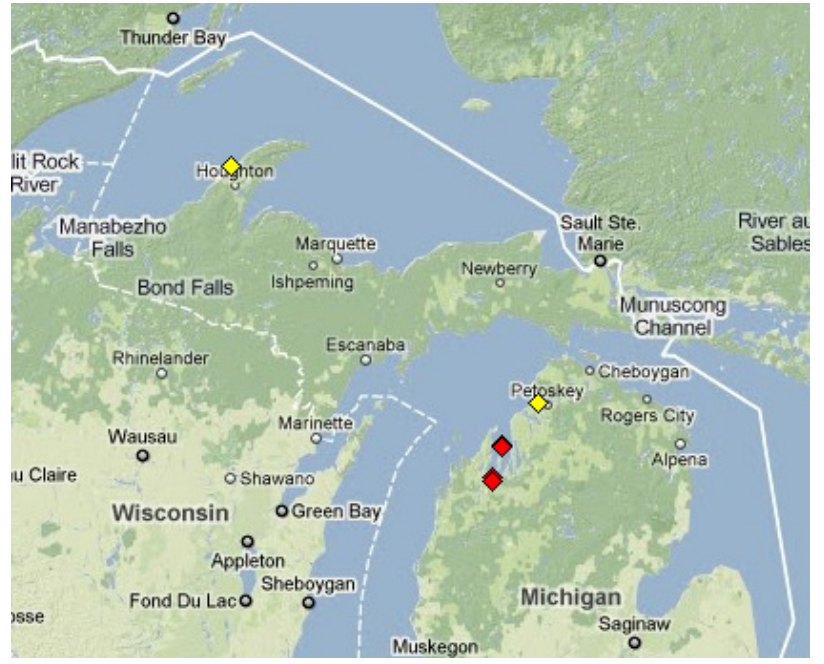

Fig. 7. 2010 U-GLOS deployment sites including five offshore buoys and one land station. Yellow icons indicate active status and red icons indicate inactive.

A typical buoy deployment involves connecting the full mooring assembly to the buoy and introducing the buoy to the water near a small craft launch ramp. Dock-side tests prove cellular connectivity and activity status of the buoy. Often large vessels are unavailable or cost-prohibitive for deployment efforts. Tests conducted at the MHL tow-tank proved the seaworthiness of the buoy hull design for towing activities (Figure 8) behind small craft and characterized a speed envelope within which the current hull design is safe for towing. A small boat is then used to tow the buoy, mooring line, and clump weight to the mooring site. At the GPS identified site, the mooring line is fully extended and water depth is verified. At this time, the clump weight is released and the installation is concluded. One further check on buoy internet connectivity is conducted before returning to shore. A standard installation can be accomplished within one working day.

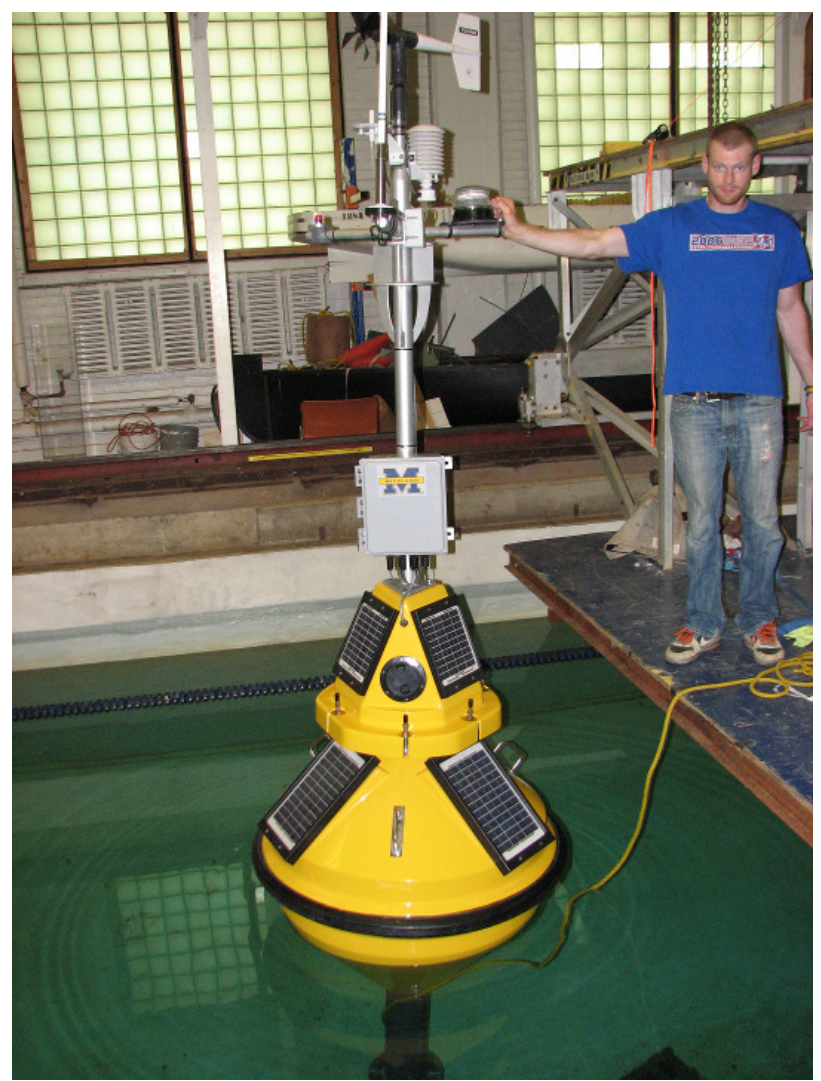

Fig. 8. Tow tests were conducted at the UMich MHL Physical Modeling Basin.

\section{CONCLUding REMARKS}

Due to the successful deployments and continued production of real-time data products, the UMich Biological Station has funded a new buoy for deployment in Douglas Lake to support environmental studies and sensor development conducted at the field station. In addition, the MTRI plans to deploy a second TIDAS buoy in Lake Superior at the east side of the Keweenaw peninsula to monitor the Keweenaw Peninsula Waterway. The additional buoys, scheduled for deployment over the summer of 2011, will bring the U-GLOS system to a total of eight monitoring buoy in Lake Superior and Lake Michigan.

This paper provided a brief history of the MHL GLOS involvement, as well as the design and fabrication of offshore buoy platforms and web-based data interaction tools for monitoring environmental conditions on the Great Lakes. The research goal of these developments is to provide a low-cost sensor platform capable of supporting environmental scientific data needs.

\section{ACKNOWLEDGMENT}

This work is supported through grants from GLOS, MTRI, ACT, DTE, Northwestern College, Michigan Sea Grant, and the Grand Traverse Band of Ottawa and Chippewa Indians, the cities of Petoskey and Harbor Springs, Irish Boat Shop and Walstrom Marine. 
The authors would like to extend their appreciation to Mr. Edward Celkis for electrical integration and his work on the data logging and communications scheme, and Mr. Nick Wild and Mr. Joe Wild for composite fabrication, paint, and mechanical integration, and Alex Ogdon for assistance during tow-tank operations.

\section{REFERENCES}

[1] U. Rowley, "COBIA: The Next Generation Buoy a Modular Approach," in OCEANS 2008, 15-18 2008, pp. 1 -6.

[2] B. Taft, M. Burdette, R. Riley, B. Hansen, W. Wells, D. Maxwell, and T. Mettlach, "Development of an NDBC Standard Buoy," in OCEANS 2009, MTS/IEEE Biloxi - Marine Technology for Our Future: Global and Local Challenges, 26-29 2009, pp. $1-10$.

[3] H. U. Sverdrup and W. H. Munk, Wind, Sea and Swell: Theory of Relations for Forecasting. U.S. Hydrographic Office, 1947.

[4] M. Longuet-Higgins, D. Cartwright, and N. Smith, "Observations of the Directional Spectrum of Sea Waves Using the Motions of a Floating Buoy," in Ocean Wave Spectra. Prentice-Hall, New Jersey, 1963, pp. $111-132$.

[5] K. Steele and M. Earle, "Directional ocean wave spectra using buoy azimuth, pitch, and roll derived from magnetic field components," vol. 16 , no. 4 , oct 1991 , pp. $427-433$.

[6] M. Tucker, Waves in Ocean Engineering: Measurement, Analysis, Interpretation. Ellis Horwood, 1991.
[7] R. Snay, M. Chin, D. Coner, T. Soler, C. Zervas, J. Oyler, M. Craymer, S. Gutman, C. Shum, K. Cheng, and C. Kuo, "Great Lakes Continuous GPS (CGPS) Network for Geodynamics, Meteorology and Safe Navigation," in Weikko A. Heiskanen Symposium in Geodesy: Celebrating 50 years in Geodetic Science at the Ohio State University, Columbus, Ohio, USA, 2002

[8] L.-C. Wu, D.-J. Doong, B.-C. Lee, C. C. Kao, and Y.-P. Lin, "Wave measurements using GPS," in OCEANS 2009, MTS/IEEE Biloxi Marine Technology for Our Future: Global and Local Challenges, 26-29 2009, pp. $1-6$.

[9] J. Hong, K. Back, U. Park, D. Lee, and S. Cha, "Determination of ocean datum using GPS buoy observation data," in International Society for Photogrammetry and Remote Sensing, vol. 37, no. Part B8, 2008, pp. 685-688.

[10] E. Cardellach, D. Behrend, G. Ruffini, and A. Rius, "The Use of GPS buoys in the Determination of Oceanic Variables," vol. 52, pp. 1113$1116,2000$.

[11] A. Schneider, "Near Shore Wireless Communication System for Sensor Buoys," in OCEANS 2006, 18-21 2006, pp. $1-5$.

[12] J. Wallinga, N. Pettirew, and J. Irish, "The GoMOOS Moored Buoy Design," in OCEANS 2003. Proceedings, vol. 5, 22-26 2003, pp. 2596 -2599 Vol.5.

[13] NDBC, "Handbook of Automated Data Quality Control Checks and Procedures," National Data Buoy Center, Stennis Space Center, Mississippi, Tech. Rep. 09-02, August 2009.

[14] T. Consi, G. Barske, H. Bootsma, T. Hansen, J. Janssen, J. Kipp, V. Klump, R. Paddock, D. Szmania, and J. Waples, "The Great Lakes Urban Coastal Observing System (GLUCOS): Results of First Deployments in Coastal Lake Michigan," in OCEANS 2007, sept. 2007, pp. 1 